\title{
Invasive Mammary Paget Disease with no Underlying Breast Carcinoma
}

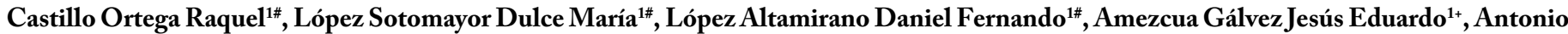 \\ Dono $^{2}$, Lopez-Garcia Carlos $\mathrm{A}^{1+}$, López de Luna Nancy Gabriela ${ }^{1}$ and Gómez Macías Gabriela Sofía ${ }^{1,3_{+}}$ \\ ${ }^{1}$ Tecnológico de Monterrey, Hospital San José TecSalud, Pathology Service, Mexico \\ ${ }^{2}$ Department of Pathology and Laboratory Medicine, McGovern Medical School, University of Texas Health Science Center at Houston, Houston, Texas, USA \\ 3Hospital Universitario de la UANL, School of Medicine, Mexico \\ "Analyzed data, collected data, wrote the paper \\ +Analyzed data, collected data, conceived the paper
}

\begin{abstract}
Introduction: Mammary Paget disease (MPD) usually presents as a neoplasm confined to the epithelium with underlying in situ or infiltrating breast carcinoma. Invasive Mammary Paget Disease with no underlying breast carcinoma (InvMPD) is a rare subtype of MPD that manifests as dermatosis on the nipple's skin. We present a case clinical, radiological, and histopathological characteristics of an InvMPD in a female patient.

Case presentation: A 42-year-old woman with a family history of breast cancer consulted with an erythematous lesion on the nipple's skin. Imaging studies revealed a circumscribed lesion consistent with fibroadenoma, which was confirmed by histology. Incisional biopsy and nipple excision revealed an InvPMD.

Discussion: MPD is a rare neoplasm that represents 1-3\% of all primary breast malignancies. Less frequently, MPD can rarely develop dermal infiltration without underlying carcinoma (invMPD). Five cases of InvMPD have been reported in the literature; therefore, we report the sixth case of InvMPD in a 42-year-old woman.

Conclusion: InvMPD is a rare clinical entity that should be considered in cases with no carcinoma in situ or invasive in breast tissue after an extensive radiological and histologically sampling of the nipple is performed.
\end{abstract}

Abbreviations: MPD: Mammary Paget disease; invMPD: invasive Mammary Paget disease; DCIS: ductal carcinoma in-situ; IDC: invasive ductal carcinoma; EMA: epithelial membrane antigen; CK7: cytokeratin 7 .

\section{Introduction}

Mammary Paget disease is a rare intraepithelial carcinoma characterized by erythematous and eczematous lesion with serohematic nipple discharge [1]. Most cases are associated with an underlying carcinoma of the breast [2].

Three types of mammary Paget disease have been described [1]: the classic form, related to the spread through the lactiferous ducts of underlying cancer [2]; the secondary, a rare form derived from invasive carcinoma that spreads directly to the epidermis of the nipple and, [3] the invasive manifestation, a controversial type, as it has been reported to lack a relationship with another breast cancer [4,5]. In the current report, we described a case of invasive mammary Paget disease with no underlying breast carcinoma.

\section{Case Presentation}

A 42-year-old female with a family history of breast cancer consulted complaining of skin changes on the right breast erythema and scaling with nipple serohematic discharge (Figure 1). There was no palpable breast masses nor lymphadenopathy. Ultrasound, mammography, and magnetic resonance were performed and a well-circumscribed nodule in the upper external quadrant was found, categorized as BI-RADS 4A

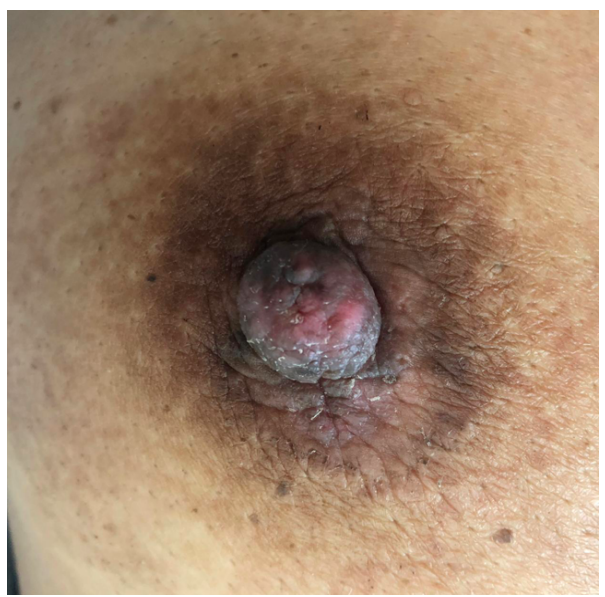

Figure 1. Clinical presentation. Erosion, redness, and scaling crust in the central portion of the right nipple noted in the patient

*Correspondence to: Gómez Macias Gabriela Sofia, Tecnológico de Monterrey, Hospital San José TecSalud, Pathology Service, Mexico; Hospital Universitario de la UANL, School of Medicine, Mexico, E-mail: dra.gabrielagomez@tecsalud.mx

Key words: breast cancer, mammary paget disease, invasive mammary paget disease, dermal infiltration

Received: April 06, 2021; Accepted: April 16, 2020; Published: April 20, 2020 
(Figure 2). The nodule biopsy demonstrated, a fibroadenoma. Incisional biopsy of the nipple showed cells in the epidermis with abundant clear cytoplasm, big nuclei with granular chromatin, and prominent nucleoli (Figure 3). Immunohistochemistry demonstrated positive epithelial membrane antigen (EMA) and cytokeratin 7 (CK7) with negative p63 and HMB-45. Therefore, the patient was diagnosed with a mammary Paget disease (MPD).

The patient underwent a mastectomy and sentinel lymph node dissection. Macroscopic examination of the breast identified nipple erythema and an $8 \mathrm{~mm}$ well-circumscribed nodule in the upper external quadrant. A detailed histologic examination of the fibrous zones was performed, in which an $8 \mathrm{~mm}$ fibroadenoma (previously biopsied specimen) was observed. Also, another $2 \mathrm{~mm}$ fibroadenoma was identified. Moreover, a radial scar and moderate ductal hyperplasia were found. The nipple histologic examination confirmed the incisional biopsy findings, an intraepidermal neoplasm characterized by cells with enlarged nuclei with pale cytoplasm arranged in a pagetoid pattern and directly beneath it, there was invasive cancer into the dermis which formed little glands and nests (Figure 4). No carcinoma in situ or another focus of infiltrating carcinoma was observed. The invasive neoplasm was categorized as an infiltrating carcinoma, not special type grade 2 with a $3 \mathrm{~mm}$ depth invasion. Both estrogen and progesterone receptors were positive in $90 \%$ of the cells, Her2/Neu negative (1+), and the Ki67 index was 10\%. Surgical margins and the sentinel lymph node were negatives (Figure 5).

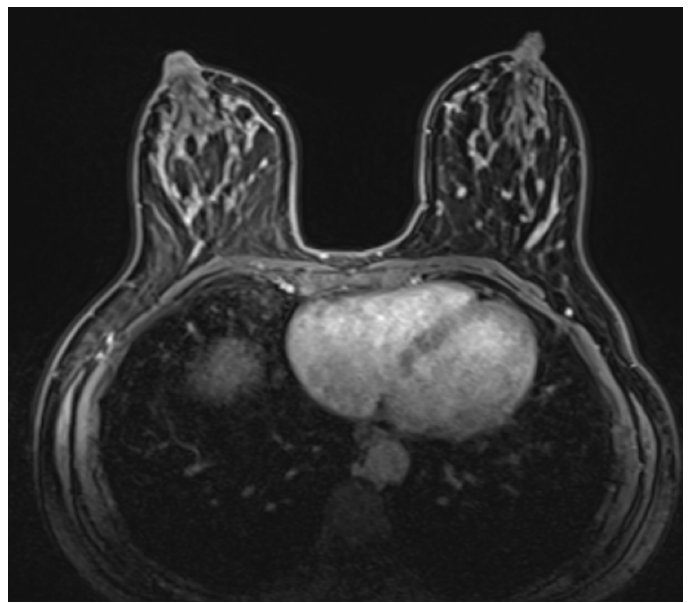

Figure 2. MRI Showed a 7-mm mass in the upper external quadrant of the right breast, which was biopsied and diagnosed as a fibroadenoma

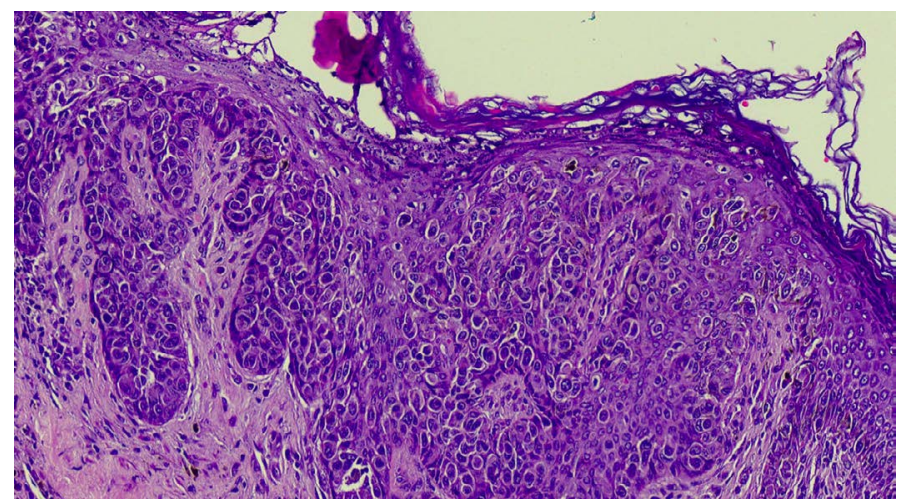

Figure 3. Incisional biopsy. Showed intraepidermal proliferation of large, atypical, palestaining cells morphologically consistent with Paget's disease

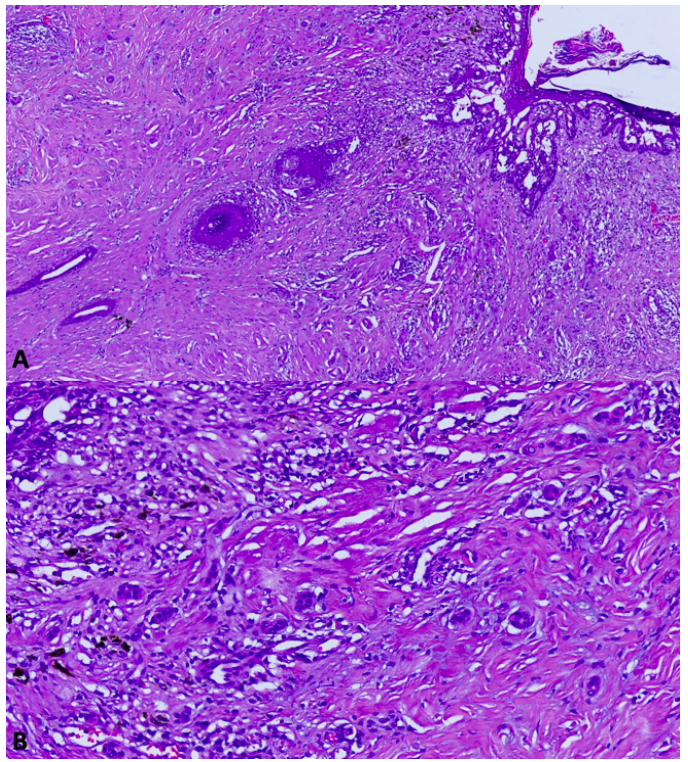

Figure 4. Mastectomy, nipple section. A. Acantholytic pattern of Paget disease, B. Direct invasion into the subjacent dermis in forms of glands and nests

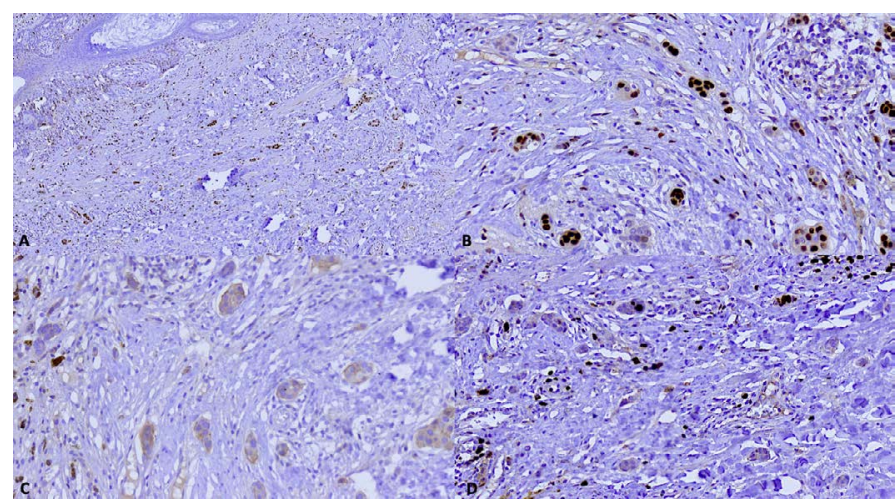

Figure 5. Immunohistochemistry profile A. Estrogen receptors positive in $90 \%$ of the cells B. Progesterone receptor-positive in $90 \%$ of the cells. C. Her $2 /$ Neu was negative (1+). D. $\mathrm{Ki}-67$ was positive in $10 \%$ of the cells

\section{Discussion}

MPD is a rare clinical entity, representing $1 \%$ to $3 \%$ of breast tumors [6]. MPD was first reported in 1856, by Velpau, when describing an eczematous lesion on the nipple's skin [7]. Later in 1874, Sir James Paget established an association between the presence of malignancy in the breast and dermatological changes in the nipple $[3,8,9]$.

Clinically, MPD manifests as a chronic, erythematous, thickened, and eczematous lesion located in the nipple-areola complex. Sometimes dermatosis may be accompanied by serohematic discharge [7], as observed in the presented case.

MPD diagnosis is performed by the correlation of clinical features and histopathological findings of the nipple and areola's lesion. Histologically, the infiltration of large, round, or oval epithelial malignant cells into the nipple's skin shows abundant pale cytoplasm, pleomorphism, and a hyperchromatic nucleus with a prominent nucleolus [10]. MPD is a carcinoma-in-situ confined to the nipple's epidermis. It rarely invades the dermis and is associated with underlying ductal carcinoma in more than $95 \%$ of cases, which may be invasive or in-situ $[11,12]$. However, in recent years, clinical variants of the disease 
have been reported to invade the dermis or lack an association with ductal carcinoma in-situ (DCIS) or invasive carcinoma. Thus, invasive mammary Paget disease with no underlying breast carcinoma is the rarest manifestation of the disease with scarce reported cases [13].

More than one mechanism by which MPD can arise has been postulated: the majority representing contiguous epidermotropic transport of preexisting DCIS or invasive ductal carcinoma (IDC) via the large lactiferous ducts, and cases with no underlying DCIS or IDC probably arising from a pluripotent cell or epidermal keratinocyte undergoing metaplasia and malignant transformation within the epidermis, and subsequently invading through the basement membrane into the superficial dermis [14-16], as observed in the presented case.

We present a case compatible with invasive MPD in a 46-yearold female patient with a family history of breast cancer, which after exhaustive imaging and tissue sampling examination, was not associated with underlying carcinoma. Invasive Paget's disease with no underlying carcinoma (invMPD) has only been reported in 5 cases in the literature. The first case was reported by Chao et al. [17] in 2003. Table 1 describes the clinicopathological characteristics of the published cases of ivnMPD.

\section{Conclusion}

MPD is usually associated with underlying breast carcinoma. InvMPD is the rarest manifestation of MPD that should be considered in cases with no in-situ or invasive carcinoma after extensive imaging and histological sampling is performed. We emphasize the importance of an accurate diagnosis and recommend close clinical follow-up in this group of patients due to the limited information regarding its clinical and prognosis significance.

\section{Declarations}

\section{Conflict of Interest}

The authors have nothing to declare.

\section{Ethics Approval and Consent to Participate}

Case reports in our institution do not require approval from the Ethics Committee.

\section{Consent for Publication}

Case reports in our institution do not require consent for publication.

Table 1. Published cases of ivnMPD without an underlying carcinoma

\begin{tabular}{|c|c|c|c|c|c|c|}
\hline & & Chao 2003 & Duan 2012 & Hanna 2013 & Lee 2014 & Castillo 2020 \\
\hline Sex & & M & F & F & $\mathrm{F}$ & $\mathrm{F}$ \\
\hline Age & & 60 & 52 & 47 & 58 & 42 \\
\hline \multirow[b]{2}{*}{ Clinical symptoms } & Nipple discharge & NS & Yes & No & NS & Yes \\
\hline & Skin changes & Yes & Yes & No & Yes & Yes \\
\hline Laterality & & Left & NS & Left & NS & Right \\
\hline \multirow{5}{*}{ Diagnostic approach } & Mammogram & NS & Negative & NS & NS & Negative \\
\hline & Chest X-rays & NS & Negative & NS & NS & NS \\
\hline & Abdominal CT & NS & Negative & NS & NS & NS \\
\hline & Liver ultrasound & NS & Negative & NS & NS & NS \\
\hline & Magnetic resonance & NS & NP & NS & NS & Negative \\
\hline \multirow{7}{*}{$\mathrm{IHC}$} & CK7 & NS & NS & Positive & NS & Negative \\
\hline & S100 & Negative & NS & Negative & NS & NP \\
\hline & HMB-45 & NS & NS & NS & NS & Negative \\
\hline & EMA & NS & NS & NS & NS & Positive \\
\hline & P63 & NS & NS & NS & NS & Negative \\
\hline & AE1 & Positive & NS & NS & NS & NP \\
\hline & CEA & Positive & NS & NS & NS & NP \\
\hline \multirow{2}{*}{$\begin{array}{l}\text { Characteristics of the } \\
\text { noninvasive component } \\
(\mathrm{cm})\end{array}$} & Length & NS & 5.3 & NS & 1.4 & NS \\
\hline & Ulceration & NS & NS & NS & NS & No \\
\hline \multirow{7}{*}{$\begin{array}{l}\text { Characteristics of the } \\
\text { invasive component }\end{array}$} & Depth (mm) & NS & 0.9 & 0.35 & 1.5 & 3 \\
\hline & Length (mm) & NS & 3.7 & NS & 1.2 & NS \\
\hline & Grade & NS & 3 (Lagios grading System) & $\mathrm{NE}$ & NS & 2 (SBRM/Nottingham) \\
\hline & ER & NS & Positive & Positive & NS & Positive in $90 \%$ \\
\hline & PR & NS & Positive & Positive & NS & Positive in $90 \%$ \\
\hline & Her $2 /$ neu & NS & Positive & $\begin{array}{c}\text { Indeterminate }(2+) \text {; FISH: } \\
\text { noncontributory }\end{array}$ & NS & Negative $(1+)$ \\
\hline & Ki-67 & NS & NS & $\mathrm{NE}$ & NS & Positive in $10 \%$ \\
\hline Lymph node & & Sentinel, negative & Positive, isolated cells & NA & NA & Negative \\
\hline \multirow[t]{4}{*}{ Treatment } & Surgical & $\begin{array}{c}\text { Radical mastectomy } \\
\text { and sentinel lymph } \\
\text { node }\end{array}$ & $\begin{array}{c}\text { Segmentectomy, reexcision } \\
\text { and sentinel lymph node }\end{array}$ & $\begin{array}{l}\text { Bilateral prophylactic } \\
\text { mastectomy }\end{array}$ & $\begin{array}{l}\text { Modified radical } \\
\text { mastectomy }\end{array}$ & $\begin{array}{l}\text { Simple mastectomy and sentinel } \\
\text { lymph node }\end{array}$ \\
\hline & Radiotherapy & NS & Yes & NS & No & No \\
\hline & Hormonal therapy & NS & NS & NS & No & No \\
\hline & Chemotherapy & NS & No & NS & No & No \\
\hline Follow-up (months) & & NS & 25 & NS & 199 & 5 \\
\hline
\end{tabular}

F: female, M: male, ER: estorgen receptor, PR: progesterone receptor, NS: not specified, NA: not applicable, NP: not performed, IHC: immunohistochemistry. 


\section{Competing Interests}

The authors have no competing interests to declare.

\section{Funding}

No funding was required for this study.

\section{Acknowledgments}

We would like to thank Dr. Jaime Tamez for providing us with clinical information about the patient.

\section{References}

1. Sato T, Muto I, Oya T, Sakai T (2017) Invasive Paget's disease of the male nipple: a case report. J Surg Case Rep 2017: rjx137. [Crossref]

2. Duan X, Sneige N, Gullett AE, Prieto VG, Resetkova E, et al. (2012) Invasive paget disease of the breast: clinicopathologic study of an underrecognized entity in the breast. Am J Surg Pathol 36: 1353-1358. [Crossref]

3. Dixon AR, Galea MH, Ellis IO, Elston CW, Blamey RW (1991) Paget's disease of the nipple. Br J Surg 78: 722-723.

4. Ozerdem U, Swistel A, Antonio LB, Hoda SA (2014) Invasive Paget disease of the nipple: a brief review of the literature and report of the first case with axillary nodal metastases. Int J Surg Pathol 22: 566-569. [Crossref]

5. Yim JH, Wick MR, Philpott GW, Norton JA, Doherty GM (1997) Underlying sdpathology in mammary Paget's disease. Ann Surg Oncol 4: 287-292. [Crossref]

6. Dubar S, Boukrid M, Bouquet de Joliniere J, Guillou L, Vo QD, et al. (2017) Paget's Breast Disease: A Case Report and Review of the Literature. Front Surg 4: 51. [Crossref]
7. Gaurav A, Gupta V, Koul R, Dabas S, Sareen R, et al. (2018) Practical consensus recommendations for Paget's disease in breast cancer. South Asian J Cancer 7: 83-86. [Crossref]

8. Seema S, Fentiman IS (2009) Paget's Disease of the Nipple. Women's Health 5: $397-$ 402 .

9. Bart JP (1971) On Disease of the Mammary Areola Preceding Cancer of the Mammary Gland. CA: A Cancer Journal for Clinicians 21: 303-304.

10. Chen CY, Sun LM, Anderson BO (2006) Paget disease of the breast: Changing patterns of incidence, clinical presentation, and treatment in the U.S. Cancer 107: 1448-1458. [Crossref]

11. Yim JH, Wick MR, Philpott GW, Norton JA, Doherty GM (1997) Underlying pathology in mammary Paget's disease. Ann Surg Oncol 4: 287-292. [Crossref]

12. Duan X, Sneige N, Gullett AE, Prieto VG, Resetkova E, et al. (2012) Invasive Paget Disease of the Breast: clinicopathologic study of an underrecognized entity in the breast. Am J Surg Pathol 36: 1353-1358. [Crossref]

13. Caliskan M, Gatti G, Sosnovskikh I, Rotmensz N, Botteri E, et al. (2008) Paget's disease of the breast: the experience of the European institute of oncology and review of the literature. Breast Cancer Res Treat 112: 513-521. [Crossref]

14. Hanna M, Jaffer S, Bleiweiss IJ, Nayak A (2013) Minimally invasive mammary Paget's disease without an underlying breast carcinoma. Virchows Arch 463: 471-473. [Crossref]

15. Jang N, Kang S, Bae YK (2018) Mammary Paget's disease without underlying malignancy of the breast. Yeungnam Univ J Med 35: 99-103. [Crossref]

16. Cohen C, Guarner J, DeRose PB (1993) Mammary Paget's disease and associated carcinoma. An immunohistochemical study. Arch Pathol Lab Med 117: 291-294. [Crossref]

17. Chao C, Edwards MJ, Wolfson S, Sewell C, Edwards D, et al. (2003) Paget's disease of the male breast: an unusual case of dermal invasion. Breast $J$ 9: 254. [Crossref]

Copyright: $\odot 2021$ Raquel CO. This is an open-access article distributed under the terms of the Creative Commons Attribution License, which permits unrestricted use, distribution, and reproduction in any medium, provided the original author and source are credited. 